\title{
Mitoni sebagai Tradisi Budaya dalam Masyarakat Jawa
}

\author{
Fitri Nuraisyah, Hudaidah \\ Jurusan Pendidikan Sejarah \\ Fakultas Keguruan dan Ilmu Pendidikan \\ Universitas Sriwijaya \\ Email: fitrinuraisyah.94@gmail.com
}

\begin{abstract}
This article discusses the Javanese tradition in the form of mitoni, the writing of this article aims to analyze the mitoni tradition carried out by people in Java, starting from the preparation before carrying out the mitoni tradition ceremony to the stage of implementing the mitoni tradition. The method used in writing this article is a literature study which is used as a source of data taken from journals and digital books, besides that the data collection technique also uses interview techniques conducted to actors who have carried out the mitoni tradition. The result of writing an article is in the form of a tradition which means that it is a habit that is carried out from the ancestors and then passed on from generation to generation from one generation to the next. In this article, we discuss the mitoni tradition. Mitoni is a tradition carried out by the Javanese people when a mother is pregnant with her first child at the age of seven months. This mitoni tradition usually includes the preparation of tools and materials before carrying out the mitoni tradition ritual, then doing the mitoni tradition starting from the bathing stage, splitting coconut ivory, changing seven kinds of cloth, selling dawet ice and rujak. Then when bathing, the dipper used is made of coconut shell. Furthermore, this article also discusses the meaning of the mitoni tradition which is also called tingkeban.
\end{abstract}

Keywords: Mitoni, Cultural Traditions, Javanese Community

\section{Pendahuluan}

Indonesia adalah sebuah negara yang memiliki beribu-ribu pulau dengan beragam kebudayaan, suku bangsa, dan tradisi di setiap daerahnya disertai dengan keunikan yang dimiliki di masing-masing daerah. Salah satu tradisi yang dimiliki ialah tradisi mitoni yang dimiliki masyarakat Jawa ${ }^{1}$. Masyarakat yang ada di Jawa memiliki beragam kebudayaan yang di dalamnya masih terkandung nilai-nilai kearifan lokal, salah satunya adalah tradisi yang dilakukan saat kehamilan hingga ke tahap melahirkan, misalnya

\footnotetext{
${ }^{1}$ Marliyana, Iskandarsyah, dan Wakidi, “Tradisi Mitoni Masyarakat Jawa di Desa Marga Kaya Kabupaten Lampung Selatan,” PESAGI 4, no. 1 (2016).
} 
Mitoni sebagai Tradisi Budaya dalam Masyarakat Jawa |Fitri Nuraisyah, Hudaidah

selamatan untuk bayi yang baru lahir (selamatan brokohan), selamatan untuk bayi yang berusia 5 hari (sepasaran), selamatan untuk bayi yang usinya 35 hari (selapanan), selamatan untuk bayi yang berusia 3 bulan 15 hari (telunglapan), tradisi 7 bulan kehamilan (mitoni), dan tradisi saat bayi berusia 1 tahun (ngetahuni) ${ }^{2}$.

Pelaksanaan selamatan kehamilan dalam bentuk sebuah tradisi merupakan bentuk rasa syukur serta memohon doa supaya calon bayi bisa mengalami pertumbuhan dengan sehat serta ketika hendak dilahirkan tidak menghadapi rintangan dan lahir dengan selamat. Selamatan yang dilakukan saat sang ibu mengandung seorang anak dapat berupa: mapati, mitoni, dan maluhi ${ }^{3}$.

Tradisi adalah semua yang meliputi kepercayaan, ajaran, kebiasaan, serta adat yang diwarisi dari nenek moyang ke generasi penerus secara turun temurun. Mitoni merupakan tradisi yang dimiliki oleh masyarakat Jawa untuk memperingati tujuh bulan usia kandungan individu, mitoni sendiri berasal dari bahasa Jawa yaitu kata pitu yang memiliki arti tujuh. Oleh karena itu tradisi ini dilaksanakan pada kehamilan tujuh bulan. Upacara mitoni hanya dilaksanakan pada kehamilan anak pertama, sehingga pada kehamilan anak kedua, ketiga, dan seterusnya tradisi mitoni ini tidak dilakukan ${ }^{4}$.

Tradisi juga dapat diartikan sebagai adat kebiasaan ataupun suatu proses kegiatan yang menjadi hak milik bersama di dalam suatu kelompok masyarakat, tradisi juga dilakukan secara terus-menerus dalam suatu masyarakat, dan dapat menjadi identitas suatu masyarakat. Selain itu ada juga yang namanya tradisi lisan, artinnya sebuah tradisi yang disampaikan secara terus-menerus dari satu generasi ke generasi selanjutnya yang disampaikan melalui lisan ${ }^{5}$.

Adapun di daerah-daerah lain, tradisi mitoni sering kali disebut dengan tingkeban yang dalam pelaksanaannya sudah disesuaikan dengan

${ }^{2}$ Yohanes Boanergis, Jacob Daan Engel, dan David Samiyono, "Tradisi Mitoni Sebagai Perekat Sosial Budaya Masyarakat Jawa,” Jurnal Ilmu Budaya 16, no. 1 (2019): 49-62.

${ }^{3}$ M. Yusuf Amin Nugroho et al., Ensiklopedia Kebudayaan Wonosobo (Bimalukar Kreativa, 2020).

${ }^{4}$ Wiranoto, Cok Bakal Sesaji (Surabaya: CV Jakad Publishing, 2018).

${ }^{5}$ R. Sibarani, "Pendekatan Antropolinguistik Terhadap Kajian Tradisi Lisan," Jurnal Ilmu Budaya 1, no. 1 (2015): 1-17. 
Mitoni sebagai Tradisi Budaya dalam Masyarakat Jawa |Fitri Nuraisyah, Hudaidah

adat, mulai dari hari pelaksanaanya yang ditentukan di hari Selasa atau hari Sabtu dan dilakukan di tanggal yang ganjil berdasarkan kalender Jawa, seperti tanggal 7 dan tanggal 15 di waktu siang hari pada pukul 11 siang. ${ }^{6}$

Tradisi Mitoni yang dilakukan saat usia kehamilan 7 bulan, yang hanya dilakukan untuk anak pertama memiliki tujuan dalam pelaksanaanya berupa memberikan keselamatan bagi bayi saat berada dalam kandungan, saat sudah dilahirkan, dan hingga dewasa. Sehingga upacara mitoni dapat memberikan simbol bahwa anak akan selalu diberikan keberkahan oleh Yang Maha Esa. Tradisi mitoni bagi masyarakat Jawa sangat penting dilakukan, adapun dalam pelaksanaanya ada banyak hal yang harus dipersiapkan sebelum upacara mitoni dilakukan, di antaranya yaitu mulai dari persiapan alat dan bahan, hidangan makanan, persiapan kain yang akan digunakan misalnya beragam kain yang di batik dengan motif yang berbeda ${ }^{7}$.

Selain itu, tradisi ini dilakukan dengan tujuan untuk meminta permohonan agar diberi keselamatan bagi calon ibu dan calon anaknya. Di dalam rangkaian pelaksanaan tradisi mitoni juga mengundang keluarga, kerabat, dan tetangga untuk turut serta dan menyaksikan pelaksanaan tradisi mitoni yang dilakukan saat calon ibu mengandung anak pertama di usia kandungan yaitu tujuh bulan ${ }^{8}$.

\section{Metode Penelitian}

Metode yang penulis gunakan yaitu metode deskriptif. Menurut pendapat Travers (1978) metode deskriptif digunakan dengan tujuan memberikan gambaran mengenai sifat sesuatu yang sedang terjadi pada saat penelitian dilakukan dan memberikan pemeriksaan mengani sebab-sebab dari gejala tertentu ${ }^{9}$. Adapun dalam penggalian data yang didapatkan yaitu melalui teknik wawancara terhadap pelaku yang pernah menjalankan tradisi mitoni, dan menggunakan sumber lainnya seperti buku dan jurnal.

\footnotetext{
${ }^{6}$ Puji Rahayu dan Dkk, Tradisi-tradisi Islam Nusantara Perspektif Filsafat dan Ilmu Pengetahuan (Semarang: Forum Muda Cendikia, 2019).

${ }^{7}$ F. Setyaningsih, "Bentuk dan Makna Upacara Manusian Yadnya Mitoni dengan Tradisi Jawa," Jurnal Agama Hindu 25, no. 2 (2020): 276-89.

${ }^{8}$ K.H. Baidawi, Sejarah islam di Jawa (Yogyakarta: Araska, 2020). Utama, 2005).

${ }^{9}$ H. Umar, Riset SDM dalam Organisasi Husein Umar (Jakarta: Gramedia Pustaka
} 
Mitoni sebagai Tradisi Budaya dalam Masyarakat Jawa |Fitri Nuraisyah, Hudaidah

Wawancara adalah sebuah pembicaraan yang mengarah kepada sebuah permasalahan tertentu meliputi: tanya jawab secara lisan yang melibatkan 2 orang atau lebih serta bertatap muka, dan mendengarkan keterangan dari narasumber secara langsung saat melakukan wawancara ${ }^{10}$. Adapun menurut Dexter (1985) wawancara merupakan pembicaraan yang memiliki tujuan untuk memperoleh informasi mengenai seseorang, sebuah kejadian, sebuah kegiatan, sebuah perasaan dan motivasi serta informasi mengenai kepedulian ${ }^{11}$.

\section{Hasil dan Pembahasan}

Tradisi Mitoni adalah keadaan seorang wanita yang mengalami kehamilan di usia 7 bulan, sehingga dilakukan sebuah upacara atau ritual yaitu dengan melaksanakan tradisi mitoni yang meliputi tahap pemandian oleh 7 orang, setelah dimandikan kemudian dilakukan pergantian kain sebanyak 7 kain, tahap selanjutnya yaitu menjatuhkan kelapa gading dan di belah menjadi 2, kemudian dilakukan pemecahan telur, lalu menjual es dawet dan rujak yang akan di beli oleh keluarga, saudara, kerabat, dan teman temannya (Wawancara Sarinah, 2021). Mitoni adalah tradisi yang dilakukan oleh masyarakat yang ada di tanah Jawa, kemudian tradisi ini dilakukan untuk memperingati usia kehamilan sang ibu yaitu berada pada usia tujuh bulan (Wawancara Sabariyah, 2021). Mitoni adalah keadaan suami dan istri yang baru menikah, kemudian sang istri mengandung anak pertama di usia kandungan ke-7 bulan dilakukan sebuah ritual tradisi mitoni, akan tetapi jika usia kehamilan sudah lewat dalam usia 7 bulan maka tidak bisa dilakukan tradisi mitoni (Wawancara Kosim M, 2021).

Mitoni adalah sebuah tradisi yang dilakukan berupa ritual saat seorang wanita mengandung dengan usia kandungan 7 bulan. Prosesi pelaksanaan mitoni dapat meliputi: pemandian ibu hamil dengan air yang sudah dicampur dengan bunga setaman dan dalam pemandian di selipkan doa-doa agar bisa mendapatkan rahmat dan keberkahan dari Tuhan, supaya sang anak di dalam kandungan dapat lahir secara sehat, selamat, tidak

${ }^{10}$ Wiranoto, Makna Simbolik Cok Bakal dalam Upacara Adat Masyarakat Jawa Serta Implikasi Sosial Umat Hindu di Kabupaten Banyuwangi (Surabaya: CV Jakad Publishing, 2019).

${ }^{11}$ M. Nazir, Metode Penelitian (Jakarta: Ghalia Indonesia, 1998). 
Mitoni sebagai Tradisi Budaya dalam Masyarakat Jawa |Fitri Nuraisyah, Hudaidah

memiliki kekurangan dalam anggota tubuh, dan mendapatkan rasa kebahagiaan dikehidupannya kelak ${ }^{12}$.

Berdasarkan sejarahnya tradisi mitoni sudah ada sejak zaman pemerintahan seorang bernama Prabu Jayabaya, yang mengisahkan adanya seorang pasangan suami istri yang memiliki nama Niken Satingkeb dan Sadiyo (punggawa di kerajaan Kediri). Niken melahirkan 9 anak dari rahimnya akan tetapi tidak ada satu pun dari anaknya tersebut yang hidup, sehongga mereka pergi ke seorang raja bernama Jayabaya menceritakan cerita hidupnya dan meminta agar bisa memiliki anak kembali serta tidak mengalami kejadian yang terjadi dimasa lalunya. Sang Raja Jayabaya akhirnya memberikan sebuah petunjuk untuk Niken Satingkeb supaya melakukan 3 ritual yaitu: mandi setiap hari rabu, mandi setiap hari sabtu, mandi suci di sore hari sekitar jam 17.00. Selain itu alat mandi yang digunakan yaitu berupa gayung tempurung kelapa dan dalam proses pemandian diselipkan doa-doa ${ }^{13}$.

Pelaksanaan tradisi mitoni pada masyarakat Jawa biasanya dilakukan saat kehamilan berusia 7 bulan memiliki rangkaian acara dalam perspektif agama islam meliputi: pembacaan ayat suci Al-Qur'an terutama surah Yusuf dan surah Maryam, melakukan khataman Al-Qur'an, melakukan tahlilan, berdoa dan berzikir bersama-sama, serta menyantap makanan yang telah dihidangkan bersama-sama. Tradisi mitoni menggambarkan bahwa seseorang bisa mendapatkan pendidikan sejak berada di kandungan sang ibu dengan melakukan tradisi ini mulai dari proses pemandian dengan air yang dicampurkan dengan bunga setaman dan dibacakan doa-doa saat prosesi pemandian, yang bertujuan untuk meminta permohonan kepada Allah SWT. supaya anak mendapatkan keberkahan dan rahmat serta dapat lahir secara sehat walafiat dan selamat ${ }^{14}$. Adapun mitoni juga sering kali disebut tingkeban yang memiliki sebuah arti yaitu selamatan pada saat kehamilan berusia tujuh bulan, kata tingkeb memiliki arti yaitu telah genap atau sudah saatnnya atau juga bisa diartikan bahwa jika bayi lahir di usia tujuh bulan dalam kandungan, hal ini telah di pandang wajar ${ }^{15}$.

${ }^{12}$ Muhammad Mustaqim, "Pergeseran Tradisi Mitoni: Persinggungan Antara Budaya dan Agama," Jurnal Penelitian 11, no. 1 (2017): 119-40.

${ }^{13}$ Mustaqim.

${ }^{14}$ Subaidi, Pendidikan Islam Risalah Ahlussunnah Wal Jama'ah An Nahdliyah Kajian Tradisi Islam (Jepara: Uninus Press, 2019).

${ }^{15}$ Sholikhim, Ritual dan Tradisi Islam Jawa (Yogyakarta: Narasi, 2010). 
Mitoni sebagai Tradisi Budaya dalam Masyarakat Jawa|Fitri Nuraisyah, Hudaidah

Adapun persiapan yang dilakukan sebelum melakukan tradisi mitoni (Wawancara Sarinah, 2021) antara lain:

1. Kelapa Gading

2. Tujuh kain

3. Tujug gayung air sumur

4. Bunga setaman (7 warna)

5. Telur

Selain itu ada pula persiapan menurut (Wawancara Kosim M, 2021) sebelum melakukan tradisi mitoni yaitu:

1. Harus mempersiapkan dua buah kelapa Gading yang di gambar dengan sepasang wayang laki laki yaitu arjuna dan wayang perempuan yaitu Sumbadra.

2. Mengambil air dari tujuh sumur, banyaknya air dari satu sumur yaitu sebanyak satu gayung disetiap sumur.

3. Bunga tujuh warna. Bunga ini dicampurkan dengan air yang sudah diambil dari tujuh sumur.

Menurut ibu Sabariyah (Wawancara, 2021), persiapan tradisi mitoni dapat meliputi:

1. Menyiapkan air dari tujuh sumur

2. Bunga tujuh warna

3. Kelapa gading yang kecil

4. Telur

5. Tujuh kain

6. Es Dawet dan Rujak

Selain persiapan alat, bahan dan perlengkapan, di dalam pelaksanaan tradisi mitoni juga diperlukan penetapan waktu pelaksanaan yang ditentukan oleh calon ayah dan calon ibu. Waktu pelaksanaan tradisi mitoni yang ditetapkan harus sesuai dengan hari baik dalam hitungan kalender Jawa, misalnya hari senin kliwon, hari kamis kliwon, ahad pon ${ }^{16}$.

Adapun untuk tanggal pelaksanaan tradisi mitoni ditetapkan di tanggal yang ganjil serta tidak melewati bulan purnama, misalnya pada tanggal ganjil meliputi tiga, lima, tujuh, sembian, sebelas, tiga belas, dan tanggal lima belas. Tradisi mitoni ini termasuk ke dalam salah satu kepercayaan masyarakat Jawa yang beranggapan bahwa seorang bayi yang

${ }^{16}$ E. Setiawan, "Nilai Religius Tradisi Mitoni dalam Perspektif Budaya Bangsa Secara Islami," Jurnal Al-Adalah 18, no. 1 (2015): 39-52. 
Mitoni sebagai Tradisi Budaya dalam Masyarakat Jawa|Fitri Nuraisyah, Hudaidah

ada di dalam kandungan yang berusia tujuh bulan mulai mendapatkan kehidupan, oleh sebab itu diadakannya tradisi mitoni atau tingkeban untuk selamatan atas kehamilan sang ibu yang mengandung anak pertama ${ }^{17}$.

Perlengkapan bunga sebanyak 7 warna yang penggunaannya yaitu dicampurkan dengan air yang berasal dari 7 sumur berguna untuk sang calon ibu yang akan dimandikan, tujuannya agar calon ibu menjadi wangi dan bersih. Selain itu 7 kain yaitu kain jarit yang digunakan juga memiliki fungsi atau kegunaan sebagai baju ganti calon ibu saat melakukan proses mitoni. Hal ini menyimbolkan jarit sebagai tali pusar bayi sehingga, kelak saat dilahirkan bayi dapat keluar dengan lancar, dan tidak terjadi lilitan tali pusar pada bayi. Kemudian pemecahan telur yang di dapatkan dari ayam kampung dipecahkan, menyimbolkan jika sang calon ibu mengalami pecah ketuban, maka diharapkan saat itu juga bayi bisa lahir dengan selamat ${ }^{18}$.

Selanjutnya setelah dilakukan persiapan ditahap selanjutnya terdapat tahap pelaksanaan tradisi mitoni yang meliputi:

1. Siraman, pada tahap siraman ibu hamil diamndikan dengan air dan bunga setaman meliputi bunga mawar, kantil, melati, kenanga. Siraman dilakukan oleh para orang yang lebih tua atau yang sudah biasa melakukan pemandian pada tradisi mitoni. Siraman yang pada ibu hamil yang sedang melaksanakan tradisi mitoni, dilakukan 7 kali siraman dengan tujuan supaya kelak ketika bayi lahir dalam keadaan yang suci dan bersih $^{19}$. Di dalam tahap siraman ini dilakukan oleh 7 orang yaitu nenek, kakek, orang tua, dan mertua yang akan memandikan sang ibu hamil yang menjalankan tradisi mitoni (Wawancara Sarinah, 2021).

2. Telur ayam kampung yang telah disiapkan, kemudian dimasukkan ke dalam kain yang di pakai oleh sang ibu hamil yang menjalankan tradisi mitoni, yang dilakukan oleh suaminya. Tahapan ini

${ }^{17}$ W. Abdullah, "Kearifan Lokal Jawa dalam Tradisi Mitoni di Kota Surakarta," Journal of Language Education, Literature, and Local Culture 3, no. 1 (2021): 19-26.

${ }^{18}$ I. Baihaqi, "Karakteristik Tradisi Mitoni di Jawa Tengah sebagai Sebuah Sastra Lisan," Jurnal Arkhais 8, no. 2 (2017).

${ }^{19}$ I. Ulya, "Nilai Pendidikan dalam Tradisi Mitoni: Studi Tradisi Perempuan Jawa Santri Mendidik Anak dalam Kandungan di Pati. Jawa Tengah," Jurnal Pendidikan Islam 3, no. 1 (2018): 116-30. 
Mitoni sebagai Tradisi Budaya dalam Masyarakat Jawa |Fitri Nuraisyah, Hudaidah

melambangkan bahwa kelak saat proses bayi dilahirkan tanpa adanya rintangan dan berjalan secara lancar ${ }^{20}$.

3. Selanjutnya memasukkan kelapa gading 2 buah ke dalam kain yang di gunakan oleh sang ibu hamil yang sedang melaksanakan tradisi mitoni. Kelapa gading dimasukkan oleh sang suami sejumlah 2 buah, sudah digambar wayang Arjuna dan wayang Sumbadra. Karakter wayang yang digambarkan melambangkan agar kelak anak-anak dilahirkan memiliki karakter seperti Arjuna dan Sumbadra ${ }^{21}$. dua buah kelapa Gading yang di gambar dengan sepasang wayang laki laki yaitu arjuna dan wayang perempuan yaitu Sumbadra. Penggambaran wayang ini memiliki makna bahwa jika anaknya lakilaki kelak akan seperti Arjuna dan jika perempuan akan seperti Sumbadra yang memiliki pikiran yang luas, tidak mudah menaruh rasa cemburu, tidak mudah menerima sebuah isu yang belum diketahui kebenarannya (Wawancara Kosim M, 2021).

4. Mengganti pakaian ibu dengan 7 kain jarit, dengan motif yang berbeda selanjutnya yang menyaksikan tradisi mitoni dimintah memilihkan kain mana yang cocok dipakaikan kepada calon $i b u^{22}$. Setelah memecahkan telur dan membelah kelapa gading, calon ibu dari bayi di minta untuk mengganti pakaian menggunakan kain jarik yang sudah disiapkan sebanyak 7 kain (Wawancara Sabariyah, 2021).

5. Penjualan rujak dan dawet, para pembeli hanya boleh membayar menggunakan uang logam yang terbuat dari genteng yang di pecahkan, kemudian dibentuk menjadi bulat seperti uang logam. Setelah selesai berjualan, uang logam di masukkan ke kuali tanah liat lalu dipecahkan kembali tepat di bagian depan pintu. Hal ini bertujuan agar calon bayi kelak murah rezekinya, serta mampu dalam memenuhi kebutuhannya dan keluarganya ${ }^{23}$.

6. Menggelar jamuan dan kenduri dengan tujuan sebagai rasa bersyukur atas karunia serta rahmat yang telah diberikan Tuhan Yang Maha $239-47$.

${ }^{20}$ I. Adriana, "Neloni, Mitoni, atau Tingkeban,” Jurnal KARSA 19, no. 2 (2011):

${ }^{21}$ Retno Intani dan Novita Damayanti, "Pemaknaan Tradisi Mitoni Adat Jawa Tengah pada Pasangan Jawa dan Padang," Prosiding Konferensi Nasional Komunikasi 2, no. 1 (2018): 539-52.

${ }^{22}$ Adriana, "Neloni, Mitoni, atau Tingkeban."

${ }^{23}$ Intani dan Damayanti, "Pemaknaan Tradisi Mitoni Adat Jawa Tengah pada Pasangan Jawa dan Padang.” 
Mitoni sebagai Tradisi Budaya dalam Masyarakat Jawa |Fitri Nuraisyah, Hudaidah

Esa. Makanan yang disediakan dapat berupa tumpeng yang menyimbolkan kelak calon bayi terlahir sehat dan kuat, serta adanya lauk pauk yang disediakan diantara tumpeng tersebut. Kemudian menyediakan beragam jajanan pasar yang dipercaya akan menimbulkan kekuatan, jika jajanan pasar disediakan secara lengkap sehingga melambangkan doa dan pengharapan akan dikabulkan ${ }^{24}$.

\section{Simpulan}

Tradisi mitoni merupakan sebuah tradisi Jawa yang dilakukan pada ibu hamil yang mengandung anak pertama dan dalam usia kehamilan yaitu tujuh bulan. Dalam tradisi mitoni ini dilakukan untuk memberikan keselamatan bagi bayi saat berada dalam kandungan, saat sudah dilahirkan, dan hingga dewasa. Adapun dari segi historisnya tradisi mitoni berasal dari seorang wanita bernama Niken Satingkeb yang kehilangan 9 anaknya yang kemudian berkonsultasi dan meminta saran dari Jayabaya yang memberikan saran berupa mandi setiap hari rabu, mandi setiap hari sabtu, mandi suci di sore hari sekitar jam 17.00. Selain itu alat mandi yang digunakan yaitu berupa gayung tempurung kelapa dan dalam proses pemandian diselipkan doa-doa.

Adapun persiapan yang harus dilakukan sebelum melaksanakan tradisi mitoni ini antara lain dengan menyiapkan telur yang diperoleh dari ayam kampung, kelapa gading yang kemudian diberi gambaran karakter wayang Arjuna dan karakter wayang Sumbadra, lalu menyiapkan 7 kain jarik, bunga 7 warna, dan air yang diperoleh dari 7 sumur. Selanjutnya setelah proses persiapan selesai maka masuk ke dalam tahap pelaksanaan yang meliputi: siraman dengan air yang sudah dicampur dengan bunga 7 warna, memecahkan telur, membelah kelapa gading, mengganti pakaian menggunakan kain jarik yang telah disiapkan, berjualan es dawet dan rujak kemudian yang terakhir adalah mengadakan jamuan dan kenduri serta menyediakan jajanan pasar untuk para tamu, keluarga, sanak saudara.

${ }^{24}$ Intani dan Damayanti. 
Mitoni sebagai Tradisi Budaya dalam Masyarakat Jawa |Fitri Nuraisyah, Hudaidah

\section{Daftar Sumber}

\section{Buku}

Baidawi, K.H. Sejarah islam di Jawa. Yogyakarta: Araska, 2020.

Nugroho, M. Yusuf Amin, Agus Wuryanto, Farid Gaban, Erwin Abdillah, dan Fatkhul Wahid. Ensiklopedia Kebudayaan Wonosobo. Bimalukar Kreativa, 2020.

Rahayu, Puji, dan Dkk. Tradisi-tradisi Islam Nusantara Perspektif Filsafat dan Ilmu Pengetahuan. Semarang: Forum Muda Cendikia, 2019.

Sholikhim. Ritual dan Tradisi Islam Jawa. Yogyakarta: Narasi, 2010.

Subaidi. Pendidikan Islam Risalah Ahlussunnah Wal Jama'ah An Nahdliyah Kajian Tradisi Islam. Jepara: Uninus Press, 2019.

Umar, H. Riset SDM dalam Organisasi Husein Umar. Jakarta: Gramedia Pustaka Utama, 2005.

Wiranoto. Cok Bakal Sesaji. Surabaya: CV Jakad Publishing, 2018. - Makna Simbolik Cok Bakal dalam Upacara Adat Masyarakat Jawa Serta Implikasi Sosial Umat Hindu di Kabupaten Banyuwangi. Surabaya: CV Jakad Publishing, 2019.

\section{Journals}

Abdullah, W. "Kearifan Lokal Jawa dalam Tradisi Mitoni di Kota Surakarta." Journal of Language Education, Literature, and Local Culture 3, no. 1 (2021): 19-26.

Adriana, I. "Neloni, Mitoni, atau Tingkeban." Jurnal KARSA 19, no. 2 (2011): 239-47.

Baihaqi, I. "Karakteristik Tradisi Mitoni di Jawa Tengah sebagai Sebuah Sastra Lisan." Jurnal Arkhais 8, no. 2 (2017).

Boanergis, Yohanes, Jacob Daan Engel, dan David Samiyono. "Tradisi Mitoni Sebagai Perekat Sosial Budaya Masyarakat Jawa." Jurnal Ilmu Budaya 16, no. 1 (2019): 49-62.

Intani, Retno, dan Novita Damayanti. "Pemaknaan Tradisi Mitoni Adat Jawa Tengah pada Pasangan Jawa dan Padang." Prosiding Konferensi Nasional Komunikasi 2, no. 1 (2018): 539-52.

Marliyana, Iskandarsyah, dan Wakidi. "Tradisi Mitoni Masyarakat Jawa di 
Mitoni sebagai Tradisi Budaya dalam Masyarakat Jawa|Fitri Nuraisyah, Hudaidah

Desa Marga Kaya Kabupaten Lampung Selatan.” PESAGI 4, no. 1 (2016).

Mustaqim, Muhammad. "Pergeseran Tradisi Mitoni: Persinggungan Antara Budaya dan Agama." Jurnal Penelitian 11, no. 1 (2017): 119-40.

Nazir, M. Metode Penelitian. Jakarta: Ghalia Indonesia, 1998.

Setiawan, E. "Nilai Religius Tradisi Mitoni dalam Perspektif Budaya Bangsa Secara Islami." Jurnal Al-Adalah 18, no. 1 (2015): 39-52.

Setyaningsih, F. "Bentuk dan Makna Upacara Manusian Yadnya Mitoni dengan Tradisi Jawa." Jurnal Agama Hindu 25, no. 2 (2020): 276-89.

Sibarani, R. "Pendekatan Antropolinguistik Terhadap Kajian Tradisi Lisan." Jurnal Ilmu Budaya 1, no. 1 (2015): 1-17.

Ulya, I. "Nilai Pendidikan dalam Tradisi Mitoni: Studi Tradisi Perempuan Jawa Santri Mendidik Anak dalam Kandungan di Pati. Jawa Tengah.” Jurnal Pendidikan Islam 3, no. 1 (2018): 116-30. 